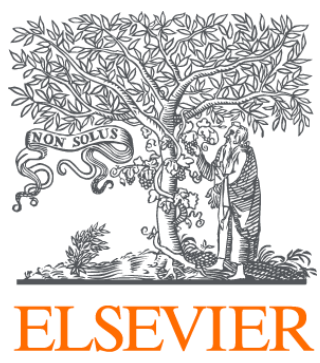

Since January 2020 Elsevier has created a COVID-19 resource centre with free information in English and Mandarin on the novel coronavirus COVID-

19. The COVID-19 resource centre is hosted on Elsevier Connect, the company's public news and information website.

Elsevier hereby grants permission to make all its COVID-19-related research that is available on the COVID-19 resource centre - including this research content - immediately available in PubMed Central and other publicly funded repositories, such as the WHO COVID database with rights for unrestricted research re-use and analyses in any form or by any means with acknowledgement of the original source. These permissions are granted for free by Elsevier for as long as the COVID-19 resource centre remains active. 


\title{
Quantum dots encapsulated with amphiphilic alginate as bioprobe for fast screening anti-dengue virus agents
}

\author{
Chung-Hao Wang ${ }^{1}$, Yi-Shiou Hsu ${ }^{1}$, Ching-An Peng* \\ Department of Chemical Engineering, National Taiwan University, Taipei, Taiwan
}

\section{A R T I C L E I N F O}

\section{Article history:}

Received 16 April 2008

Received in revised form 1 August 2008

Accepted 4 August 2008

Available online 13 August 2008

\section{Keywords}

Quantum dots

Dengue virus

Amphiphilic alginate

Drug screening

Allophycocyanin

Polybrene

\begin{abstract}
A B S T R A C T
The increasing threats of viral diseases have gained worldwide attention in recent years. Quite a few infectious diseases are still lacking effective prevention or treatment. The pace of developing antiviral agents could be expedited by the availability of quick and efficient drug screening platforms. In this study, quantum dot (QD), an emerging probe for biological imaging and medical diagnostics, was employed to form complexes with virus and used as fluorescent imaging probes for exploring potential antiviral therapeutics. Inorganic CdSe/ZnS QDs synthesized in organic phase were encapsulated by amphiphilic alginate to attain biocompatible water-soluble QDs via phase transfer. Virus employed for this study was dengue virus which is a notorious one in tropical and subtropical regions of the world. To construct a QD-virus imaging modality capable of providing meaningful information, preservation of viral infectivity after tagging virus with QDs is of utmost importance. In order to form colloidal complexes of QD-virus, electrostatic repulsion force generated from both negatively charged virus and QDs was neutralized by various concentrations of cationic polybrene. Results showed that BHK-21 cells infected with dengue viruses incorporated with QDs exhibited bright fluorescence intracellularly within $30 \mathrm{~min}$. To demonstrate the potency of QD-virus complexes as bioprobes for screening antiviral agents, BHK-21 cells were incubated for one hour with allophycocyanin purified from blue-green algae and then infected with QD-virus complexes. Based on the developed cell-based imaging assay, allophycocyanin with concentration of $125 \mu \mathrm{g} / \mathrm{mL}$ led to extremely weak intracellular fluorescence post-infection of QD-virus complexes for $30 \mathrm{~min}$. That is, the efficacy of anti-dengue viral activity of the algae extract was clearly illustrated by the inorganic-organic hybrid platform constructed in current study.
\end{abstract}

(c) 2008 Elsevier B.V. All rights reserved.

\section{Introduction}

Unlike bacteria-based infection which can be controlled by antibiotics, viruses fully relying on host cells for their replication are not so readily dealt with. The emergence and spread of viral diseases worldwide, particularly HIV/AIDS, outbreaks of severe acute respiratory syndrome (SARS) virus, and the scares of pandemic avian influenza virus seriously raise the concern that any virus strain has the potential evolving into a life-threatening pathogen. In this regard, developing fast and efficient screening technology has its merits of identifying potential drugs against viral diseases that still lack of effective prevention or treatment. Dengue virus is the typical one representing an important emerging mosquito borne disease

\footnotetext{
* Corresponding author at: Department of Chemical Engineering, National Taiwan University, No. 1, Section 4, Roosevelt Road, Taipei 106, Taiwan, ROC.

Tel.: +88623366 3063; fax: +886223623040.

E-mail address: chinganpeng@ntu.edu.tw (C.-A. Peng).

1 These authors contributed equally to this work.
}

worldwide. It has spread from being endemic in just 9 countries in 1970 to 100 countries in 2002, according to the world health report (http://www.who.int/whr/2002/en). Apparently, global population growth, urbanization, and frequent modern transportation have contributed to the increased incidence and geographic spread of dengue viruses. These diseases occur in tropical and subtropical areas of the world, where 2.5 billion people are estimated at risk for dengue virus outbreaks (Gubler and Clark, 1995). Each year, tens of millions of cases of dengue fever occur, particularly in Asia, Africa, South America, and Pacific. The fatality rate is about 5\% and there is no vaccine available for dengue virus. Control of the primary vector, Aedes aegypti, is the only method currently employed to prevent dengue virus epidemics.

The pace of exploiting antiviral agents could be expedited by the availability of quick and efficient high-throughput anti-dengue viral agent screening assays. Recently, a cell-based immunofluorescence imaging technology has been developed to identify potential anti-dengue viral therapeutic agents (Chu and Yang, 2007). They reported that inhibitors of the c-Src protein kinase hinder the assembly of dengue virions and may therefore be an effective 
therapy. It was anticipated that the new assay can be useful for identifying small molecule inhibitors of dengue virus infection and replication as well as improving understanding of dengue virus-host interaction. Although the developed assay has its merits, the process of screening antiviral agents was not quick enough because the Vero cell culture plate after the addition of dengue virus and then specific protein kinase inhibitor has to be incubated for 3 days prior to the performance of immunofluorescence staining. Moreover, anti-dengue E protein monoclonal antibody and the secondary antibody conjugated with fluorescent dye FITC have to be used for labeling the cell monolayer. This is no doubt a timeconsuming and expensive process. Fluorescent dye has been widely used for viral labeling experiments and improved our understanding of viral infection process. However, fluorophores are notorious for photobleaching and spectral overlaps, and therefore could affect the fluorescence imaging quality of dye-labeled virus since the observation time ranged from one to ten seconds before photobleach occurs. Obviously, a high fluorescence quantum yield and a large number of fluorescent photocycles before photobleach of the dye molecule occurs are the prerequisites for successfully detecting dye-labeled viral particles. Moreover, after labeling viral particles with fluorescent dyes, the number of viruses that can infect a cell most likely will be severely diminished.

In view of the drawbacks of using fluorescent dyes (Chan and Nie, 1998; Parak et al., 2005), colloidal semiconductor quantum dots (QDs) were investigated in this study to explore the potency of tagging QDs to viral particles. Thanks to excellent photostability, broad adsorption spectra, and narrow emission spectra, QDs have attracted great interests in many areas of research, from molecular and cellular biology to molecular imaging and medical diagnostics (Michalet et al., 2005 and references therein). Tri$n$-octylphosphine oxide (TOPO)-coated QD suspended in organic solvent was first converted into water-soluble QD employing synthesized amphiphilic alginate surfactants. Complexes between QDs and dengue virus, both possessing a net negative surface charge, will be formed by colloidal clustering, facilitated by positively charged polycationic compound - polybrene. In order to test if QD-virus complexes can be harnessed as diagnostic probes for fast screening potential anti-dengue viral drug candidates, allophycocyanin (protein-bound pigment) purified from a blue-green microalga Spirulina platensis was used as the model agent since it has been reported to exhibit anti-EV71 activities (Shih et al., 2003). Our results showed that the intensity of green QD images within BHK-21 cells was decreased along with the dosage increase of allophycocyanin up to $125 \mu \mathrm{g} / \mathrm{mL}$ provided one hour prior to the addition of QD-virus complexes. It was clearly illustrated that allophycocyanin possesses anti-dengue viral activity and this can be determined within half an hour after target cells incubated with dengue viruses incorporated with amphiphilic alginate coated QD in the presence of $50 \mu \mathrm{g} / \mathrm{mL}$ polybrene.

\section{Materials and methods}

\subsection{Synthesis of CdSe/ZnS QDs}

To prepare semiconductor CdSe/ZnS QDs, a mixture of $25.7 \mathrm{mg}$ of cadmium oxide (CdO, Sigma, USA), $3.88 \mathrm{~g}$ of Tri- $n$-octylphosphine oxide (TOPO, Sigma), and $2.41 \mathrm{~g}$ of hexadecylamine (HDA, Acros, Belgium) was heated to $300-320^{\circ} \mathrm{C}$ under a dry nitrogen atmosphere. After the formation of a CdO-HDA complex as indicated by the change of color from reddish to colorless, the temperature of the solution was cooled down to $260^{\circ} \mathrm{C}$ and waited for injection. A stock solution with $31.58 \mathrm{mg}$ of selenium powder (Se, Sigma-Aldrich) dissolved in $5 \mathrm{~mL}$ of tri-n-butylphosphine (TBP, Showa, Japan) was quickly injected into the solution under rigorous stirring to nucleate CdSe nanocrystals. After injection, the core solution was grown at $260{ }^{\circ} \mathrm{C}$ for approximately $5 \mathrm{~s}$ when the color of the mixture turned from colorless to slightly red. The temperature was then cooled to $200^{\circ} \mathrm{C}$ for shell growth. The shell solution containing $379.4 \mathrm{mg}$ zinc stearate (J.T. Baker, Netherlands) and $12.8 \mathrm{mg}$ sulfur powder (S, Sigma) dissolved in $5 \mathrm{~mL}$ of TBP was heated to $110^{\circ} \mathrm{C}$ for $30 \mathrm{~min}$ and then cooled to room temperature for injection. The shell solution was added dropwise into the core solution under stirring over a period of $15 \mathrm{~min}$. After addition of shell solution, the core-shell solution was cooled down to $120^{\circ} \mathrm{C}$ to anneal for $2 \mathrm{~h}$. The coreshell solution was cooled to room temperature afterwards. The CdSe/ZnS nanocrystals were precipitated by anhydrous methanol (Tedia, USA) and then stored in chloroform (Tedia) for further use.

\subsection{Preparation of amphiphilic alginate surfactant}

Sodium alginate solution (Sigma) mixed with $2 \mathrm{wt}$ \% sodium periodate (Acros) in a dark, cold chamber $\left(4^{\circ} \mathrm{C}\right)$ for $24 \mathrm{~h}$. Exclusion of light was essential for the prevention of side reaction. To obtain oxidized 2,3-dialdehydic alginate, the reaction mixture was extensively dialyzed against distilled water and subsequently freeze-dried. Two milligrams of octylamine (Acros) dissolved in $8 \mathrm{~mL}$ methanol was reacted with $0.276 \mathrm{mg} 2,3$-dialdehydic alginate dissolved in $10 \mathrm{~mL}$ phosphate buffer saline (PBS) solution containing $0.1 \mathrm{~g}$ sodium cyanoborohydride $\left(\mathrm{NaCNBH}_{3}\right.$, Acros). The reductive amination proceeded for $12 \mathrm{~h}$ with rigorous stirring at room temperature. The reaction mixture was dialyzed and subsequently freeze-dried to obtain the amphiphilic alginate surfactant.

\subsection{Encapsulation of $\mathrm{QDs}$ with amphiphilic alginate}

$0.4 \mathrm{mg}$ of CdSe/ZnS suspended in $5 \mathrm{~mL}$ of chloroform was added with $2 \mathrm{mg}$ of alginate surfactant. The mixture was sonicated in a bath for $10 \mathrm{~min}$, and then the chloroform was removed by a rotary evaporator (Eyela, Japan) at room temperature. At the end of the operation, the mixture was resuspended with PBS solution and filtered through a $0.22-\mathrm{m}$ syringe filter (Millipore, USA) to remove aggregates. The filtrate was freeze-dried to obtain the amphiphilic alginate coated quantum dots in the powder form.

\subsection{Particle size analysis}

QDs encapsulated by amphiphilic alginate (AA-QDs) were thoroughly dispersed in aqueous solution by a sonicator $(200 \mathrm{~W}, 40 \mathrm{kHz}$; Branson Ultrasonics Corporation, CT, USA) for $10 \mathrm{~min}$ and then passed through a $0.22-\mu \mathrm{m}$ syringe filter to collect non-aggregated AA-QDs which were analyzed for mean particle size and size distribution by the dynamic light scattering (Zetasizer Nano ZS, Malvern Instruments, UK) equipped with a diode-pumped solid-state laser operating at $633 \mathrm{~nm}$ wavelength as a light source. The particle size distribution and the average particle diameter were obtained from the correlation function by a regularization method included in the data analysis software package (Dispersion Technology Software 5.02, Malvern Instruments, UK).

\subsection{Zeta potential measurement}

The surface electric charge of AA-QDs, dengue virus, and QD-virus complexes was measured separately by the zeta potentiometer (Zetasizer Nano-ZS, Malvern Instruments, UK) via determining the electrophoretic mobility. The electrophoretic mobility is obtained by harnessing microelectrophoresis technique 
on the sample to measure the velocity of the particles using laser Doppler velocimetry. The isoelectric point ( $\mathrm{p} I$ ) of allophycocyanin was determined to be the $\mathrm{pH}$ at which it carries no net electric charge (i.e., zeta potential equals to zero).

\subsection{Absorption and photoluminescence spectra of $A A-Q D s$}

A UV-vis spectrophotometer (Jasco Model V-570, Japan) and a photoluminescence spectrophotometer (Jasco Model FP-6000, Japan) were used to characterize AA-QDs. UV-vis absorption spectrum of QDs was scanned in the wavelength range of $300-700 \mathrm{~nm}$. The photoluminescence of the particles was measured in the wavelength range of $400-700 \mathrm{~nm}$. The spectra were obtained with the data pitch at $5 \mathrm{~nm}$ and the scanning speed of $500 \mathrm{~nm}$ per min. All samples were placed in quartz cuvettes (1-cm path length) and the optical measurements were carried out using PBS as the reference for AA-QDs.

(a)
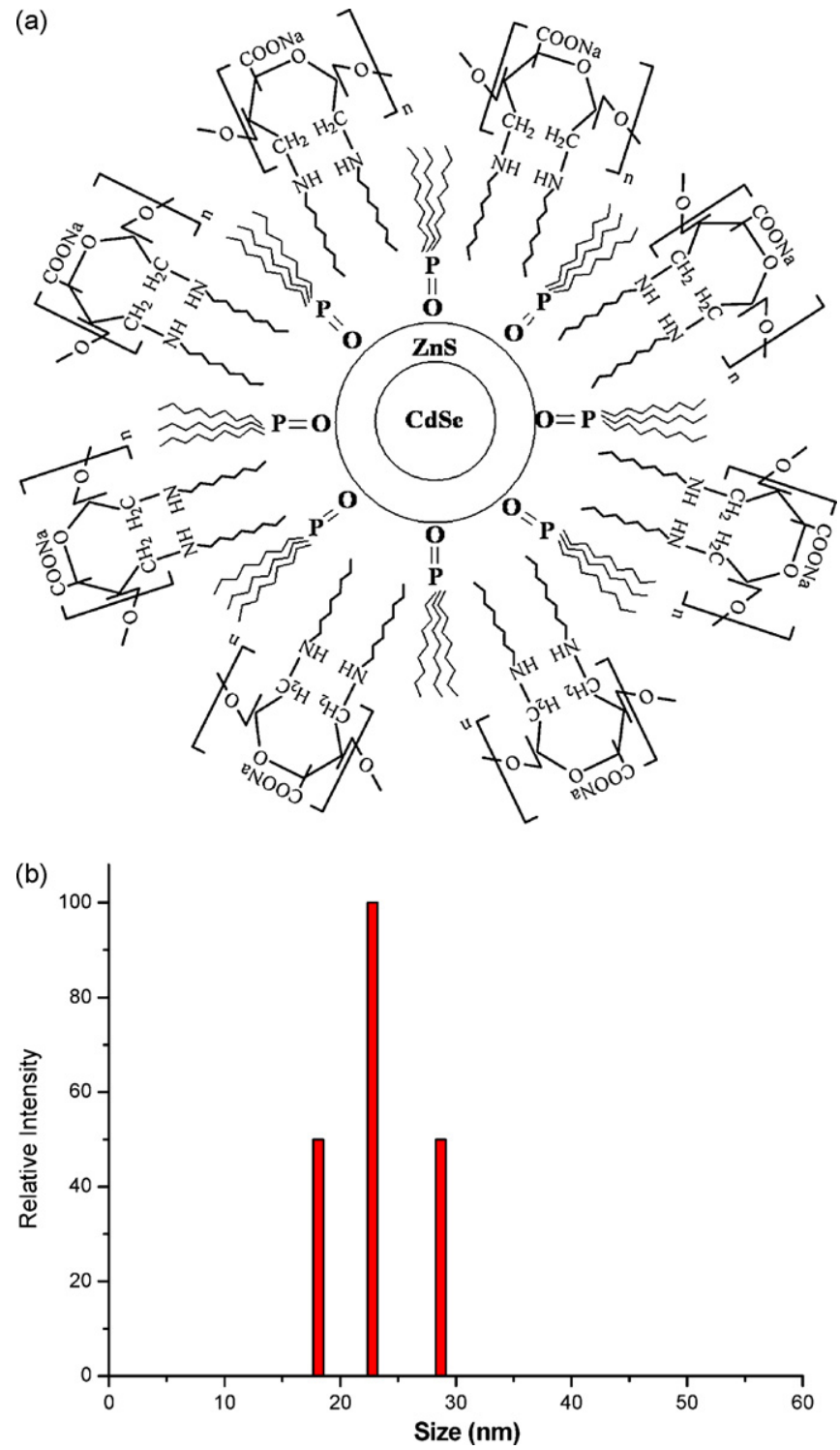

Fig. 1. (a) Schematic drawing of $\mathrm{CdSe} / \mathrm{ZnS}$ quantum dots encapsulated by amphiphilic alginate surfactant; (b) particle size distribution of AA-QDs by dynamic light scattering. After sonication, the distribution was narrowed down to the range between 18.1 and $28.7 \mathrm{~nm}$ with a mean diameter of $23.1 \mathrm{~nm}$.

\subsection{Transmission electron microscopy (TEM) analysis}

TEM specimens were made by evaporating one drop of quantum dots/virus complexes solution on carbon-coated copper grids. TEM micrographs were taken by a transmission electron microscope (JEM-1230, JOEL, Tokyo, Japan) operating at $100 \mathrm{kV}$. Phosphotungstic acid (Sigma) was used as the negative stain reagent.

\subsection{BHK-21 cells and dengue viruses}

BHK-21 cells were maintained at $37^{\circ} \mathrm{C}$ in Dulbecco's modified Eagle's medium (DMEM; HyClone, UT, USA), supplemented with $10 \%$ fetal bovine serum (FBS; HyClone). Dengue virus serotype2 strain PL046 was propagated in mosquito C6/36 cell line maintained at $30^{\circ} \mathrm{C}$ in DMEM, supplemented with $10 \% \mathrm{FBS}$,
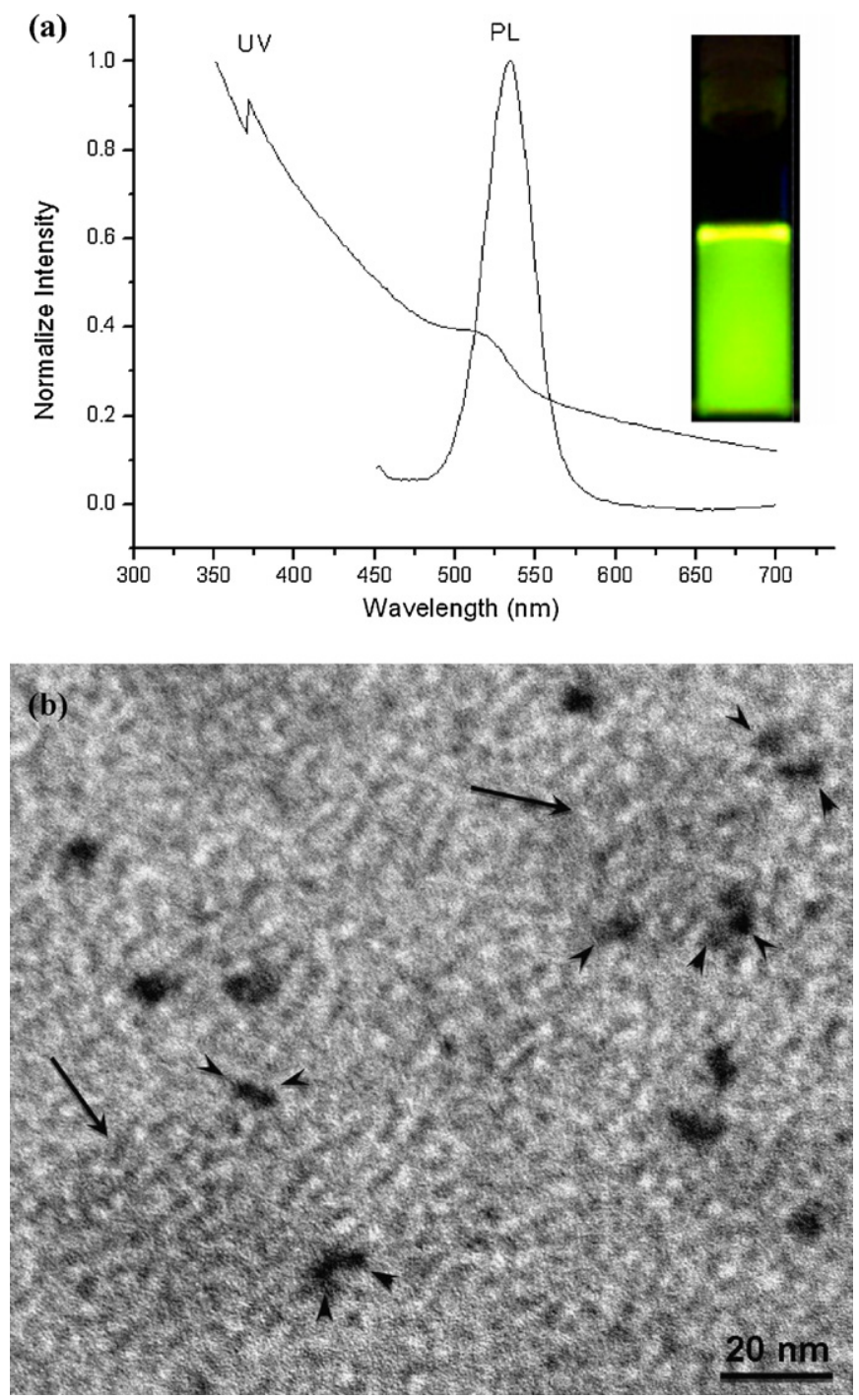

Fig. 2. (a) Photoluminescence and UV-vis spectra of AA-QDs. UV-vis absorption spectrum of AA-QDs was detected in the range of $300-700 \mathrm{~nm}$. The photoluminescence of AA-QDs was measured in the range of $400-700 \mathrm{~nm}$ with an excitation wavelength of $390 \mathrm{~nm}$. The photoluminescence with the emission wavelength peaked at $534 \mathrm{~nm}$ indicating bright green fluorescence of AA-QDs in aqueous solution shown in the inset photograph; (b) TEM image of the QD-virus complexes formed in the cationic polybrene solution. The light-color particles with the size around $40-50 \mathrm{~nm}$ are dengue virus (indicated by arrow). The dark-color particles tagged on the viral particles (indicated by arrowhead) are AA-QDs (about 10-15 nm). (For interpretation of the references to color in this figure legend, the reader is referred to the web version of the article.) 

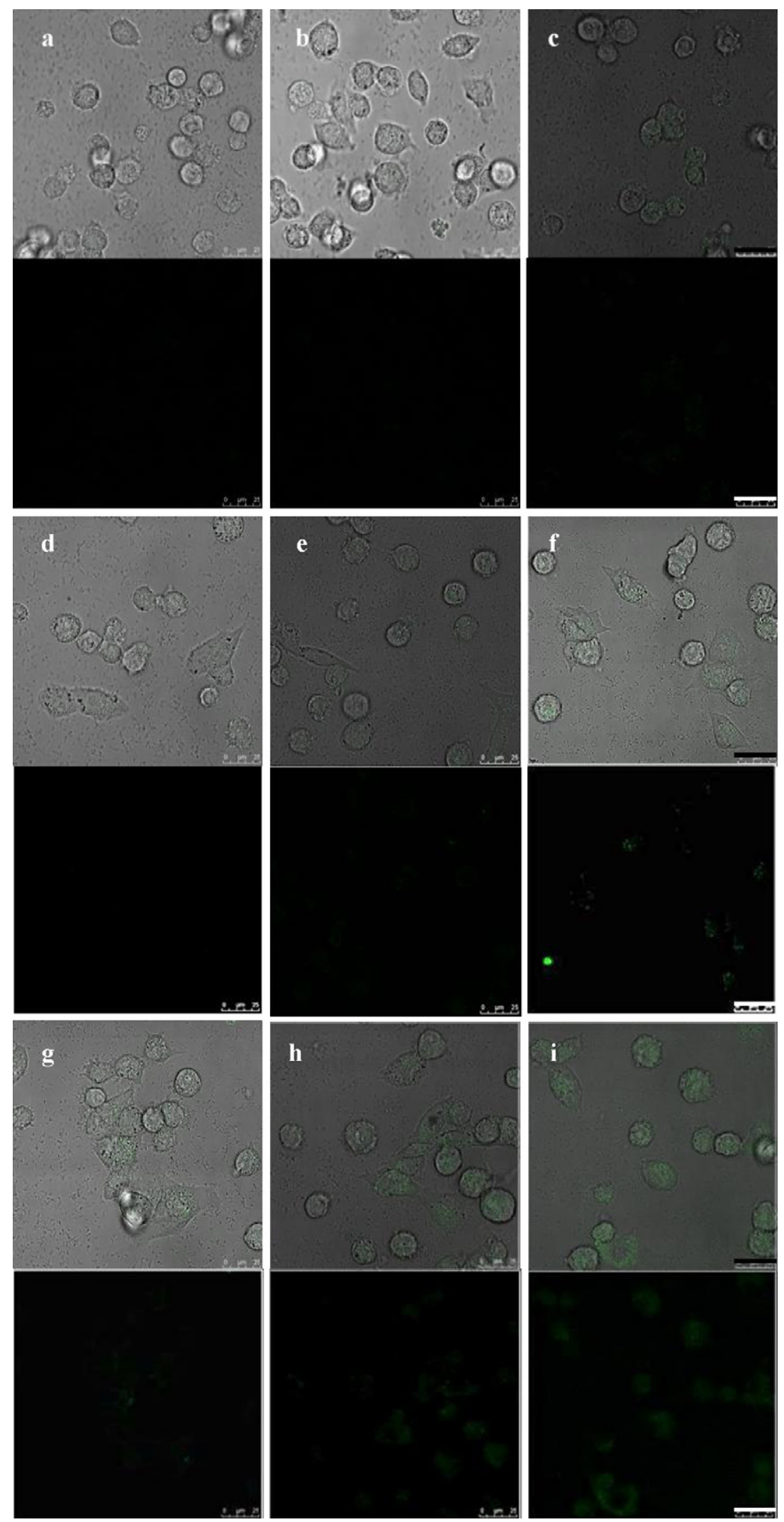

Fig. 3. Photomicrographical images of BHK- 21 cells exposed separately to AA-QDs with and without polybrene for various periods of time. (a)-(c) Images of BHK-21 cells incubated with QDs without polybrene for 30,60, and $120 \mathrm{~min}$, respectively. QD was not detected intracellularly under fluorescent confocal microscopy until 120 min post-incubation; (d)-(f) images of BHK-21 cells incubated with QDs in the presence of $10 \mu \mathrm{g} / \mathrm{mL}$ polybrene. QD was not detected intracellularly under fluorescent confocal microscopy until 60 min post-incubation. (g)-(i) Images of BHK-21 cells incubated with QDs in the presence of $50 \mu \mathrm{g} / \mathrm{mL}$ polybrene. QD was clearly detected intracellularly under fluorescent confocal microscopy after 30 min post-incubation. The normalized fluorescence intensities per selected cell area of (b)-(i) based on the fluorescence intensity per selected cell area of (a) are $1.02,1.06,0.94,2.55,3.65,1.70,3.93$, and 5.20 , respectively. Scale bar $=25 \mu \mathrm{m}$. 
penicillin $(200 \mathrm{U} / \mathrm{mL})$ and streptomycin $(100 \mu \mathrm{g} / \mathrm{mL})$. Dengue viruscontaining supernatant was first centrifuged at $10,000 \mathrm{rpm}$, and then ultracentrifuged at $100,000 \times g$ at $4{ }^{\circ} \mathrm{C}$ for $3 \mathrm{~h}$ to purify dengue virions. The titer of the virus was evaluated using BHK21 cells by the plaque assay (Liu et al., 1997).

\subsection{Inhibition of $Q D-v i r u s$ infection by algae extracts}

AA-QDs suspended in $1 \mathrm{~mL}$ DMEM medium were added into $1 \mathrm{~mL}$ dengue virus-containing medium with multiplicity of infection (MOI) of $0.1,0.5$, and 1.0 , respectively. After gentle shaking of the mixed media, polybrene (1,5-dimethyl-1,5- diazaundecamethylene polymethobromide, $M W=5000-10,000$, Sigma-Aldrich) stock solution was pipetted into the mixture to reach a final concentration of 10 and $50 \mu \mathrm{g} / \mathrm{mL}$, respectively. Then, the mixed solution was incubated at $4^{\circ} \mathrm{C}$ for $1 \mathrm{~h}$ to prevent dengue virus from losing infectivity. After the process of incorporating virus with AA-QDs, $5 \times 10^{4}$ BHK-21 cells in the exponential growth phase were replaced with the QD-virus-containing medium. After treating BHK-21 cells with the QD-virus complexes for various periods of time $(30,60$, and $120 \mathrm{~min})$, the cell culture dish was washed with PBS three times and observed under Spectral Confocal and Multiphoton System (Leica TCS SP5, Wetzlar, Germany) with the settings of objective lens $63 \times$, pinhole 1.0 , smart gain $380 \mathrm{mV}$, and
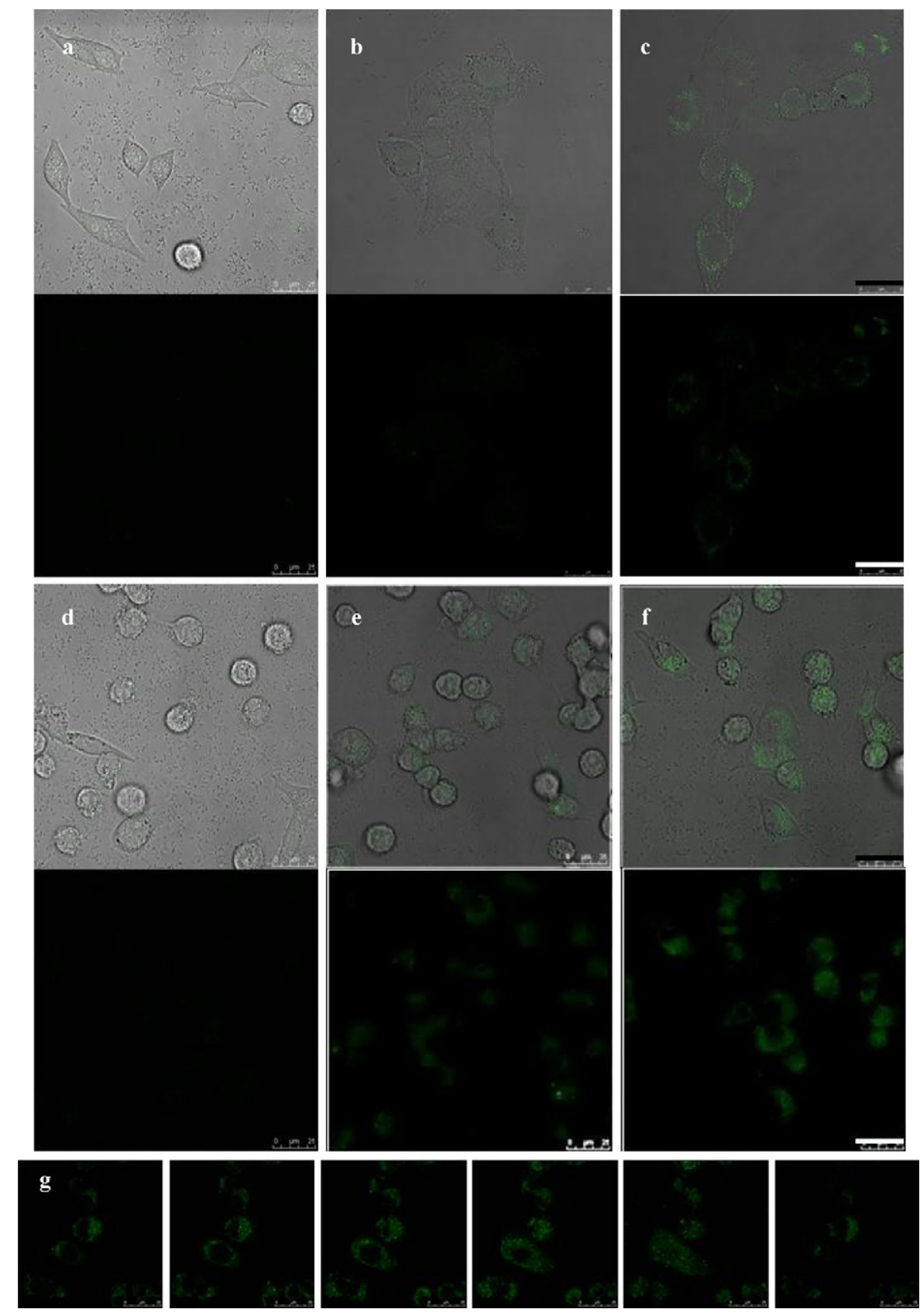

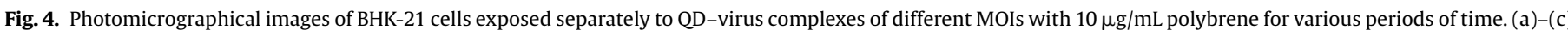

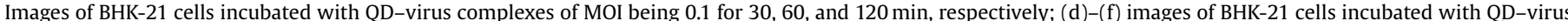

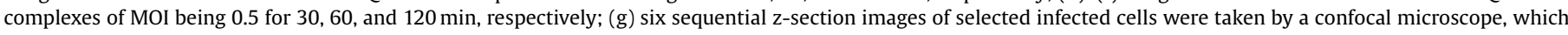

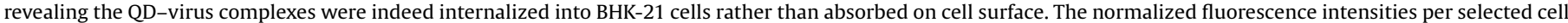
area of (b)-(f) based on the fluorescence intensity per selected cell area of (a) are 1.00, 1.33, 1.19, 2.56, and 3.54, respectively. Scale bar $=25 \mu \mathrm{m}$. 
405-nm laser ND 3. The fluorescence intensity of QDs revealed within the observed BHK-21 cells was quantitatively analyzed by the MetaMorph ${ }^{\circledR}$ imaging software(Version 7.5, Molecular Devices, USA).

In order to test if QD-virus complexes can be harnessed as diagnostic probes for fast screening potential anti-dengue therapeutic agents. Allophycocyanin (Far East Bio-Tec Co., Taipei, Taiwan) with concentration of $6.25,31.25$, and $125 \mu \mathrm{g} / \mathrm{mL}$ was used to treat BHK21 cells for one hour, and then rinsed away by PBS solution for three times. After allophycocyanin treatment, QD-virus complexes were added separately for 30,60 , and 120 min to examine the efficacy of drug screen assay proposed in this study.

\section{Results and discussion}

\subsection{QDs encapsulated with amphiphilic alginate}

Colloidal nanocrystal QDs consisting of an inorganic core/shell structure (e.g., CdSe/ZnS) surrounded by a layer of organic ligands (i.e., TOPO) can be converted into hydrophilic nanoparticles by several approaches (Bruchez et al., 1998; Chan and Nie, 1998; Dubertret et al., 2002; Mulder et al., 2006; Pinaud et al., 2004; Zhelev et al., 2006). The commonly used strategy is based on the exchange of the original organic layer with hydrophilic ligands, however the physical properties (i.e., quantum yield) are usually deteriorated through such surface modification. In this study, we demonstrated the first time that amphiphilic alginate can encapsulate $\mathrm{CdSe} / \mathrm{ZnS}$ by intercalating alginate surfactant's hydrophobic pendant moieties (i.e., octyl chains) into the hydrophobic surfactant layer (i.e., TOPO) on the QD surface, thereby resulting in the phase transfer of hydrophobic QDs from organic solvents to aqueous solution via hydrophilic backbone (i.e., alginate). The schematic drawing of the water-soluble CdSe/ZnS QDs encapsulated with amphiphilic alginate is shown in Fig. 1(a). The average size of water-soluble QDs encapsulated by alginate surfactants was determined to be $23.1 \mathrm{~nm}$ in the range of 18.1-28.7 nm shown in Fig. 1(b). As long as the number of pendant groups is sufficiently high, the linkage of amphiphilic alginate to the QD surface could be very stable and thereby lead to the physical properties of QD intact. The absorption and emission spectra of QD encapsulated with amphiphilic alginate given in Fig. 2(a) reveal higher absorbance between 525 and $550 \mathrm{~nm}$ and strong photoluminescence with the emission wavelength peaked at $534 \mathrm{~nm}$ after excited by UV-light. The inset image in Fig. 2(a) illustrates the bright green color of AA-QD in aqueous solution. To demonstrate the formation of QD-virus complexes via colloidal clustering of negatively charged QD and dengue virus in cationic polybrene solution, TEM image of QD-virus complexes was taken and showed in Fig. 2(b). In the image, the light-color particles with the size around $40-50 \mathrm{~nm}$ are dengue virus, and the dark-color particles tagged on the surface of viral particles are AA-QDs (about $10-15 \mathrm{~nm})$.

\subsection{Cell-QD interaction}

Fig. 3 showed the photomicrographical images of BHK-21 cells incubated with AA-QDs at various time periods. In Fig. 3(a)-(b), when the AA-QDs (zeta potential measurement of $-7.18 \mathrm{mV}$ ) added in cell culture dish without polybrene respectively for 30 and $60 \mathrm{~min}, \mathrm{AA}-\mathrm{QDs}$ were not detected under fluorescent microscopy after remained AA-QDs was washed off with PBS. This is due to electrical repulsion between alginate macromolecule and cell surface which are both negatively charged. However, after $120 \mathrm{~min}$ co-culture of AA-QDs and cells without the addition of polybrene, green dots representing QDs were able to be pinpointed within cellular domain (Fig. 3(c)). It is surmised that, given a longer incubation time (i.e., $120 \mathrm{~min}$ ), sufficient amount of proteins (ingredients from fetal bovine serum) adsorbed onto the surface of negatively charged AA-QDs triggered nonspecific cell binding and ensuing endocytosis. While, in Fig. 3(d)-(f), AA-QDs were started to be detected in the intracellular space $60 \mathrm{~min}$ post-incubation, in the presence of $10 \mu \mathrm{g} / \mathrm{mL}$ polybrene. This is probably because the electrostatic neutralization effect of polycationic polybrene led to nonspecific adsorption of negatively charged AA-QDs on negatively charged cell membrane. It is noteworthy that polybrene is a cationic polymer and has been reported to act by neutralizing negative charges on the surface of cells and virions to promote virus attachment and enhance viral transduction rate (Kwon and Peng, 2002). Once the concentration of polybrene increased to $50 \mu \mathrm{g} / \mathrm{mL}$, AA-QDs were able to enter the cell ports within a short period of time and
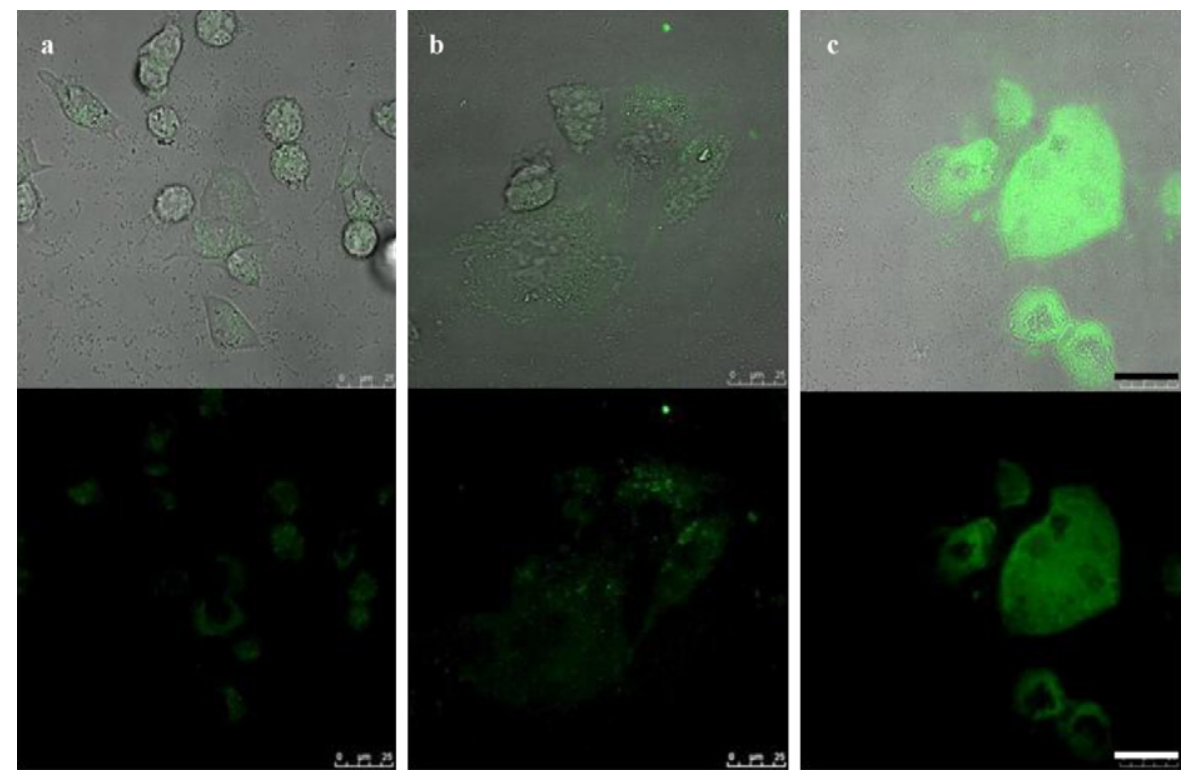

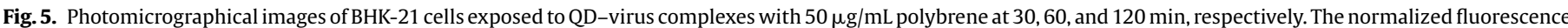

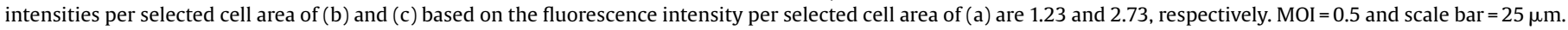


expressed green fluorescence in BHK-21 cells after 30 min of treatment.

\subsection{Effect of polybrene on infectivity of $Q D$-virus}

The QDs encapsulated with amphiphilic alignate surfactants were employed to form colloidal clusters with dengue viruses (zeta potential measurement of $-6.04 \mathrm{mV}$ ) in the presence of cationic polybrene. To determine the suitable viral concentration for the development of quick and efficient cell-based fluorescent imaging drug screening platform, various MOIs (multiplicity of infection) were employed ranging from 0.1 to 1 . Our results showed that QD-virus complexes with a net positive charge (zeta potential measurement of $+2.84 \mathrm{mV}$ ) were internalized into BHK-21 cells by receptor-mediated endocytosis, and can be detected in cellular milieu. As shown in Fig. 4(a)-(f), green fluorescent intensity expressed within BHK-21 cells due to the entrance of QD-virus was augmented in proportion to the increment of MOI (from 0.1 to 0.5 ). To confirm the QD-virus complexes were indeed internalized into BHK-21 cells rather than absorbed on cell surface, a series of photomicrographs taken by a confocal microscope along the z-axis of selected infected cells are shown in Fig. 4(g). The green fluores- cence was further enhanced when the concentration of polybrene increased from 10 to $50 \mu \mathrm{g} / \mathrm{mL}$ with MOI maintained at 0.5 (shown in Fig. 5(a)-(c)). Since preservation of viral infectivity after tagging virus with QDs is of utmost importance for QD-virus imaging modality offering meaningful information, plaque forming assays were performed with BHK-21 cells treated with intact dengue viruses and QD-virus complexes. The result (data not shown) indicated the number of plaque forming units numerated from the cells infected with QD-virus complexes was only slightly lower than the control group (i.e., dengue viruses without QDs tagging). This implies that dengue viral infectivity was retained using the method of incorporation virus with QDs in polycationic solution. This is consistent with the previous report indicating the infectivity of incompetent retrovirus as a viral gene delivery vehicle decreases slightly when mixed with QD in polycationic solution (You et al., 2006). In contrast to viruses covalently labeled with fluorescent dyes, the method developed in this study seems to be a superior one. In the case of adeno-associated virus (AAV), which is a relatively small virus ( $\sim 25 \mathrm{~nm}$ in diameter), it has been shown that for a dye-to-particle ratio higher than two, the infectious titer was severely affected, namely the number of viruses which were able to infect a cell was lowered (Seisenberger et al., 2001). It
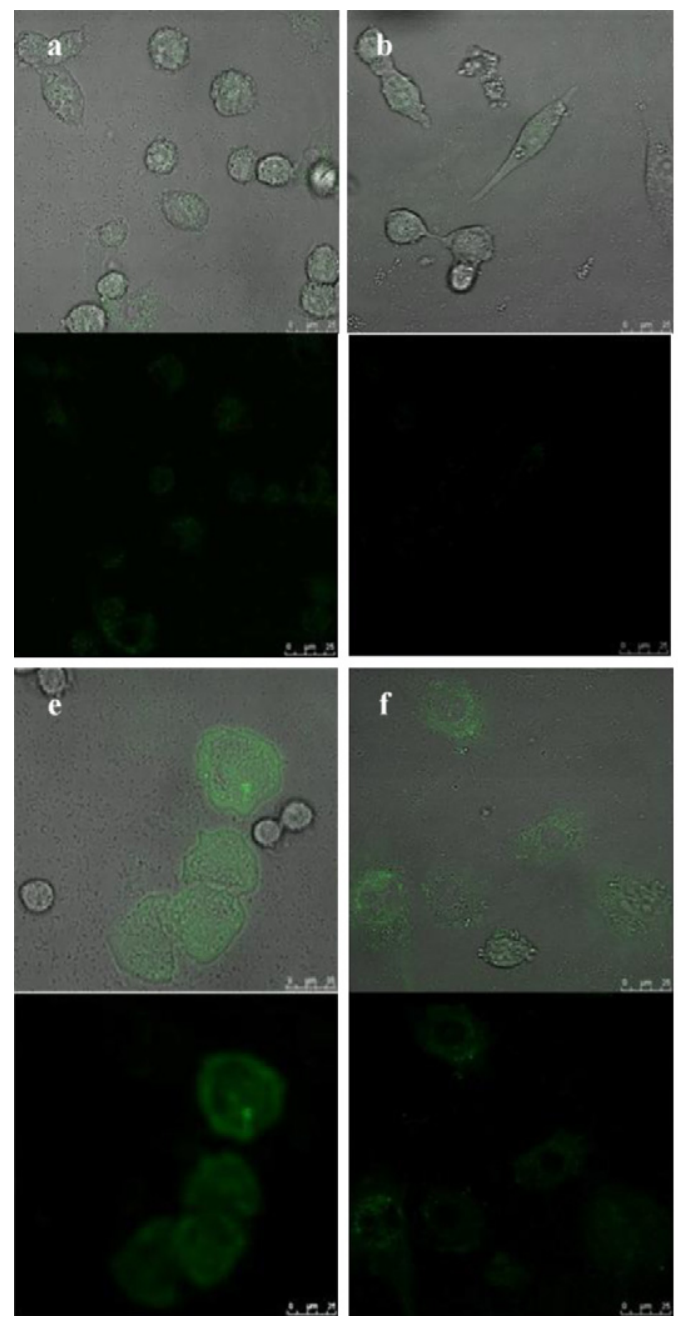
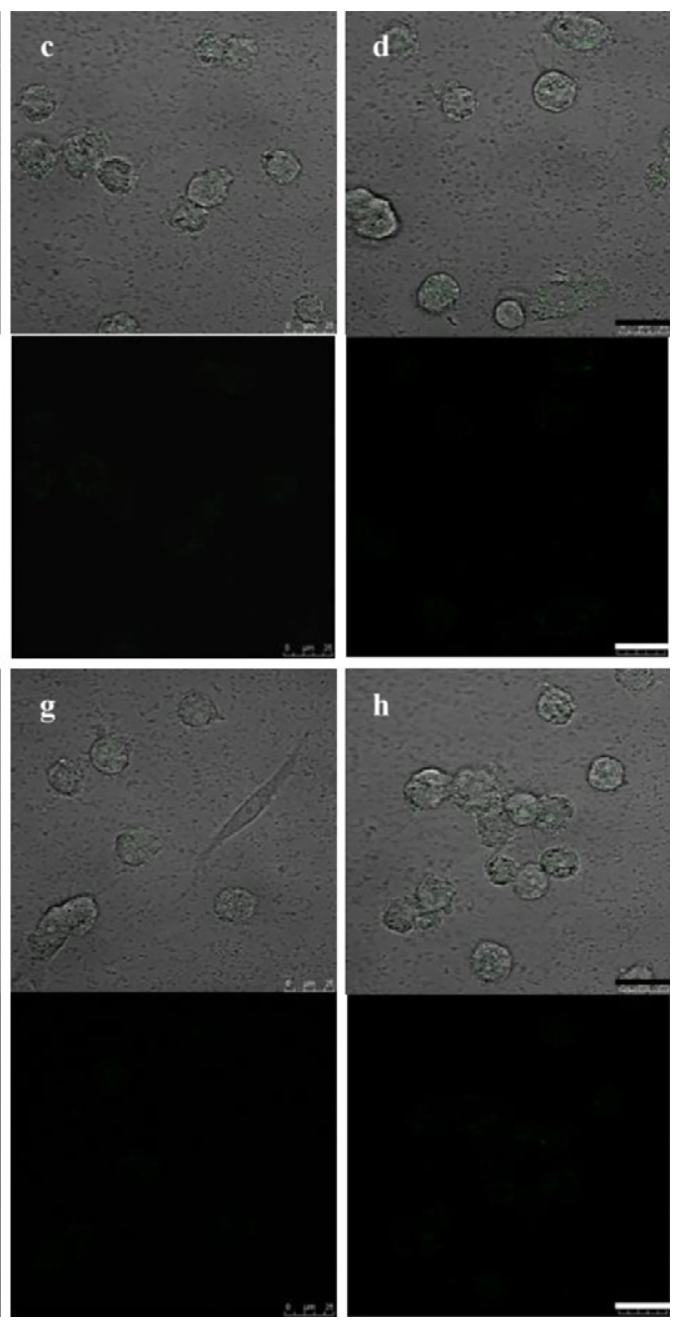

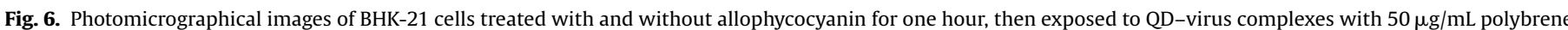

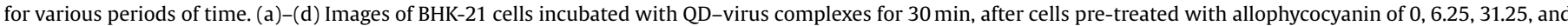

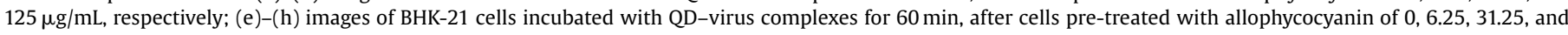

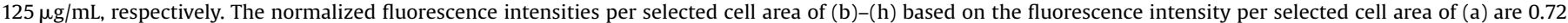
$0.66,0.54,2.92,1.02,0.66$, and 0.52 , respectively. $\mathrm{MOI}=0.5$ and scale bar $=25 \mu \mathrm{m}$. 
should be noted that the cell shape of Fig. 5(b) turned into large ones after BHK-21 cells were infected with QD-virus complexes for $60 \mathrm{~min}$. The situation gets even worse for cells treated with QD-virus complexes up to $120 \mathrm{~min}$ (see Fig. 5(c)). We speculate such cell morphological changes were caused by the viral damage of cell machinery (e.g., cytoskeleton), thereby leading to cell lysis.

In addition to the microscopy-based fluorescence technique, biochemical methods are also available to analyze the biology of the virus (Girod et al., 1999). In many of these methods, viral gene expression is determined after a certain long incubation time. Moreover, most of the methods are very time consuming and a large amount of viruses has to be used. In view of the need of polybrene for neutralizing electrostatic repulsion force between both negatively charged dengue virus and amphiphilic alginate coated $\mathrm{QD}$, it is conjectured that having QDs capped by positively charged water-soluble ligands (or polymers) to directly form complexes with viruses without the aid of polybrene probably is a feasible and much simple method.

\subsection{Antiviral activity of allophycocyanin}

According to the results shown in Fig. 5, it is reasonable to speculate that, if any potential compound has anti-dengue viral feature, the intensity of green fluorescence emitted from QD-virus complexes internalized in cells should be drastically diminished. In order to test if QD-virus complexes can be harnessed as diagnostic probes for fast screening potential anti-dengue drugs, allophycocyanin was selected as the model compound for exploring the efficacy of QD-virus imaging modality for screening anti-dengue viral therapeutic agents. Allophycocyanin has been reported to neutralize EV71-induced cytopathic effect in both human rhabdomyosarcoma cells and African green monkey kidney cells. Antiviral activity was more efficient in cultures treated with allophycocyanin before viral infection compared with that in the cultures treated after infection (Shih et al., 2003). As shown in Fig. 6(a)-(d), the intensity of green images within BHK-21 cells was decreased along with the dosage increase of allophycocyanin provided one hour prior to the addition of QD-virus complexes which were constructed in the presence of $50 \mu \mathrm{g} / \mathrm{mL}$ polybrene. It should be noted that cells incubated with QD-virus complexes for only 30 min can give a fairly clear fluorescent intensity decrease with the concentration of allophyscocyanin up to $125 \mu \mathrm{g} / \mathrm{mL}$. For cells treated with allophycocyanin higher or equal to $31.25 \mu \mathrm{g} / \mathrm{mL}$ for one hour then challenged with QD-virus complexes for $60 \mathrm{~min}$, the diminish of green fluorescence is even astonishing prominent. Compared to other anti-viral agent screening assays, the cell-based QD-virus imaging modality exploited in this study indeed has fast and efficient features for screening antiviral therapeutics. Since, the $\mathrm{p} I$ value of allophycocyanin was measured around 4.5 , a net negative charge of allophycocyanin will be revealed in the cell culture medium. Such negatively charged allophycocyanin might be associated with positively charged QD-virus complexes if free allophycocyanin remained in the culture medium. However, in our study, BHK-21 cells were only treated with allophycocyanin for $1 \mathrm{~h}$ and washed three times with PBS solution. There is no concern of allophycocyanin interference on the interaction between QD-virus complexes and cells.

\section{Conclusion}

To construct QD-virus imaging modality capable of providing meaningful information, preservation of viral infectivity after tagging virus with QDs is of utmost importance. In this study, we demonstrate the infectivity of QD-virus formed via colloidal clustering in the presence of polycationic polybrene remained intact to be internalized by cells susceptible to dengue virus. The efficacy of anti-dengue viral activity of an algal extract was clearly illustrated by the constructed inorganic-organic hybrid platform in a quick and efficient manner.

\section{Acknowledgements}

The authors thank Dr. Huan-Yao Lei (Institute of Basic Medical Sciences, National Cheng Kung University, Tainan, Taiwan) for providing dengue virus and its related information.

\section{References}

Bruchez, M.J., Moronne, M., Gin, P., Weiss, S., Alivisatos, A.P., 1998. Science 281, 2013-2016

Chan, W.C.W., Nie, S.M., 1998. Science 281, 2016-2018.

Chu, J.J.H., Yang, P.L., 2007. PNAS 104, 3520-3525.

Dubertret, B., Skourides, P., Norris, D.J., Noireaux, V., Brivanlou, A.H., Libchaber, A., 2002. Science $298,1759-1762$.

Girod, A., Ried, M., Wobus, C., Lahm, H., Leike, K., Kleinschmidt, J., Deleage, G., Hallek, M., 1999. Nat. Med. 9, 1052-1056.

Gubler, D.J., Clark, G.G., 1995. Emerg. Infect. Dis. 1, 55-57.

Kwon, Y.J., Peng, C.-A., 2002. Biotech. Bioeng. 77, 668-677.

Liu, H.S., Lin, Y.L., Chen, C.C., 1997. Acta Virol. 41, 317-324.

Michalet, X., Pinaud, F.F., Bentolila, L.A., Tsay, J.M., Doose, S., Li, J.J., Sundaresan, G., Wu, A.M., Gambhir, S.S., Weiss, S., 2005. Science 307, 538-544.

Mulder, W.J.M., Koole, R., Brandwijk, R.J., Storm, G., Chin, P.T.K., Strijkers, G.J., Donega, C.D., Nicolay, K., Griffioen, A.W., 2006. Nano Lett. 6, 1-6.

Parak, W.J., Pellegrino, T., Plank, C., 2005. Nanotechnology 16, R9-25.

Pinaud, F., King, D., Moore, H.-P., Weiss, S., 2004. J. Am. Chem. Soc. 126, 6115-6123.

Seisenberger, G., Ried, M.U., Endreb, T., Buning, H., Hallek, M., Brauchle, C., 2001. Science 294, 1929-1932.

Shih, S.R., Tsai, K.N., Li, Y.S., Chueh, C.C., Chan, E.C., 2003. J. Med. Virol. 70, 119-125.

You, J.O., Liu, Y.S., Liu, Y.C., Joo, K.I., Peng, C.A., 2006. Int. J. Nanomed. 1, 59-64.

Zhelev, Z., Ohba, H., Bakalova, R., 2006. J. Am. Chem. Soc. 128, 6324-6325. 